\title{
A recurrent de novo mutation in ATP1A3 gene in a Mexican patient with alternating hemiplegia of childhood detected by massively parallel sequencing
}

\author{
Carolina I. Galaz-Montoya1, Sofia Alcaraz-Estrada², Leopoldo A. García-Montaño3, \\ Juan C. Zenteno ${ }^{3,4}$ and Raul E. Piña-Aguilar ${ }^{5 *}$
}

${ }^{1}$ Private practice, Hermosillo, Sonora, Mexico; ${ }^{2}$ Division of Medical Genomics, Centro Médico Nacional 20 de Noviembre, ISSSTE, Mexico City, Mexico; ${ }^{3}$ Research Unit in Genetics, Instituto de Oftalmología Conde de Valencia, Mexico City, Mexico; ${ }^{4}$ Department of Biochemistry, Facultad de Medicina, Universidad Nacional Autónoma de Mexico, Mexico City, Mexico; ${ }^{5}$ School of Medicine, Medical Sciences and Nutrition, University of Aberdeen, Aberdeen, United Kingdom

\begin{abstract}
Background: Pediatric movement disorders represent a diagnostic challenge for pediatricians and pediatric neurologists due to their high clinical heterogeneity and shared common features. Therefore, specific diagnoses require different approaches including metabolic work-up and specific tests for frequent genetic conditions. Alternating hemiplegia of childhood (AHC) is an ultra-rare pediatric movement disorder, characterized by paroxysmal alternating hemiplegia, dystonia, and seizure-like episodes that can be misleading during the evaluation of a child with a movement disorder. Case report: We present a Mexican patient with abnormal movements referred to the Genetics clinic because of hyperammonemia and a possible organic acidemia. Our assessment did not find clinical features compatible with an inborn error of metabolism. A massively parallel sequencing approach with targeted panel sequencing was used to get a final diagnosis. A missense variant c.2839G $>A$ (p. Gly947Arg) located at exon 21 of ATP1A3 gene was demonstrated. This variant (rs398122887) has been previously reported as de novo producing alternating hemiplegia of childhood (AHC). Conclusions: $A H C$ is an ultra-rare syndrome presented as a movement disorder with seizure-like episodes and a unique facial phenotype. Clinicians should be aware of this combination in order to diagnose this condition in a timely manner. Massive parallel sequencing panels are emerging as the best approach to diagnose rare movement disorders and simultaneously rule out metabolic disorders and common epileptic syndromes.
\end{abstract}

Key words: Congenital paralysis. Dystonia. Hemiplegia. Neurogenetics. Movement disorders.

\section{Mutación de novo recurrente en el gen ATP1A3 en una paciente mexicana con hemiplejia alternante de la infancia detectada por secuenciación masiva en paralelo}

\section{Resumen}

Introducción: Los trastornos pediátricos del movimiento representan un reto diagnóstico para pediatras y neurólogos pediatras debido a su gran heterogeneidad clínica y características comunes compartidas. Por lo tanto, los diagnósticos es-

\section{Correspondence:}


pecificos requieren de diferentes abordajes que incluyen la búsqueda de desórdenes metabólicos y pruebas específicas para condiciones genéticas frecuentes. La hemiplejia alternante de la infancia (AHC) es un trastorno pediátrico del movimiento poco común, caracterizado por cuadros paroxísticos de hemiplejia alternante, distonía y episodios semejantes a crisis epilépticas, que pueden resultar desorientadores durante el abordaje diagnóstico de un infante con un desorden del movimiento. Caso clínico: Presentamos una paciente mexicana con movimientos anormales referida a la Clínica de Genética por hiperamonemia y una posible acidemia orgánica. Nuestro abordaje no identificó características clínicas compatibles con un error innato del metabolismo. Se utilizó un abordaje basado en secuenciación masiva en paralelo para obtener un diagnóstico final. Se demostró una variante de sentido equivocado c.2839G>A (p.Gly947Arg) localizada en el exón 21 del gen ATP1A3. Esta variante (rs398122887) ha sido previamente reportada como de novo, ocasionando AHC. Conclusiones: La AHC es un síndrome excepcionalmente raro que se presenta con un trastorno del movimiento con cuadros semejantes a crisis epilépticas y un fenotipo facial particular. Los médicos deben ser conscientes de esta combinación con el fin de diagnosticar oportunamente esta condición. Los paneles de secuenciación masiva están emergiendo como el mejor abordaje para diagnosticar trastornos del movimiento raros y, simultáneamente, descartar trastornos metabólicos y síndromes epilépticos comunes.

Palabras clave: Parálisis congénita. Distonía. Hemiplejia. Neurogenética. Trastornos del movimiento.

\section{Introduction}

Mutations affecting the ATP1A3 gene (OMIM 182350) have been associated with a group of related neurological phenotypes including four well-described syndromes: rapid-onset dystonia parkinsonism (RDP), alternating hemiplegia of childhood type 2 (AHC) (OMIM 614820), cerebellar ataxia, areflexia, pes cavus, optic atrophy, and sensorineural hearing loss syndrome (CAPOS) ${ }^{1}$, and relapsing encephalopathy with cerebellar ataxia (RECA). Defects in ATP1A3 are also associated with less specific phenotypes such as seizures, dystonia, ataxia, and psychiatric conditions ${ }^{2,3}$.

$\mathrm{AHC}$ is an autosomal dominant disease characterized by neurological symptoms, which include episodes of alternating hemiplegia, dystonia, abnormal ocular movements, autonomic dysfunction, and epileptic seizures, and impairments in speech, fine and gross motor skills. The estimated incidence of $\mathrm{AHC}$ is 1 in $1,000,000^{3,4}$. It is suggested that AHC type 2 and RDP are allelic disorders and comprise a single spectrum of a disorder associated with mutations in $A T P 1 A 3^{5}$. There are 67 pathogenic mutations in ATP1A3 gene reported in ClinVar database ${ }^{6}$ with variable neurological phenotypes.

The symptoms of AHC start before 18 months of age and have a marked variability between different individuals who recover from the episodes of hemiplegia during sleep ${ }^{4}$. AHC can be diagnosed on a clinical basis, but the verification of a mutation in ATP1A2 (OMIM 104290) or ATP1A3 genes are necessary to confirm a clinical diagnosis ${ }^{3}$.

In this case, we report a Mexican patient with a movement disorder, who was referred to us due to hyperammonemia and a possible organic acidemia. We performed next-generation sequencing of a panel of genes associated with Mendelian diseases, which led to a final diagnosis of AHC.

\section{Case report}

We report a 5-year-old girl (individual $\mathrm{II}_{2}$ ) born in Los Mochis, Sinaloa, located at the northwest of Mexico. The parents are a young couple and were under 30 years at patient conception. The mother (individual $\mathrm{I}_{2}$ ) is affected by non-celiac gluten sensitivity and polycystic ovary syndrome; the father (individual $I_{1}$ ) has periodical occupational exposure to pesticides without other medically relevant information. Proband has a healthy 7-year-old brother (individual $\mathrm{II}_{1}$, Fig. 1A).

After a full-term pregnancy (39 weeks of gestation), without complications detected in the prenatal period or during delivery, the patient was born with normal height, weight, and Apgar score. No newborn screening of any type was performed. The patient showed developmental delay during her first year of life: she achieved cephalic control at 8 months, sitting at 12 months, and fluent language at 17 months. Currently, she requires support to walk. Her movement disorder started with an episode of alternating temporary hemiplegia with abnormal eye movement lasting several hours at the age of 8 months-misdiagnosed as epilepsy and initiated antiepileptic drugs. After this event, she continued to have episodes of hemiplegia every month, which increased with time in length, severity, and frequency, reaching a maximum of 4-5 events per week. These episodes were exacerbated by excitation and food with high sugar content. 


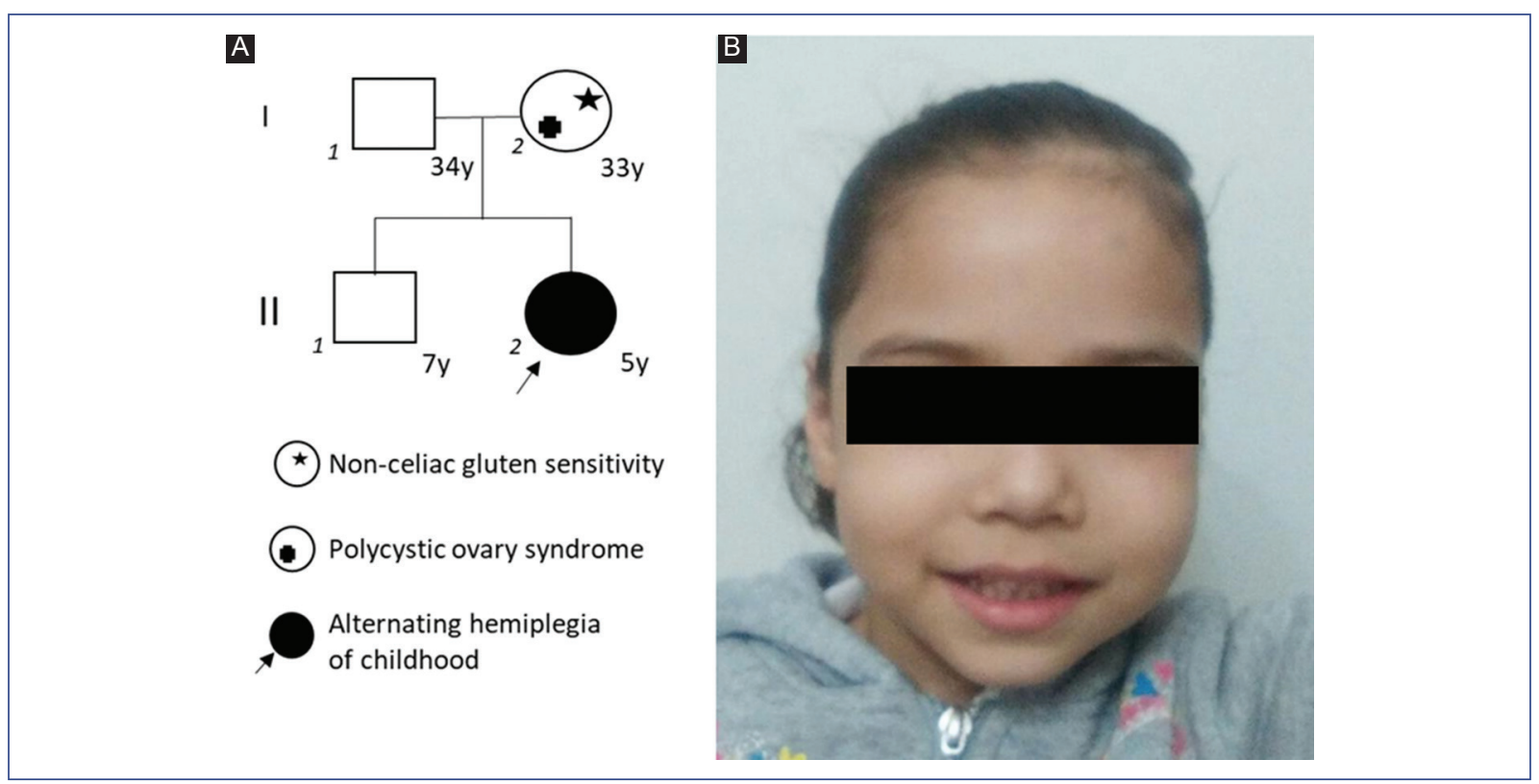

Figure 1. (A) Family pedigree. Proband (II2) is marked by an arrow. In this family, a simple case cannot support a specific pattern of inheritance of the neurological condition; molecular diagnosis confirmed a de novo presentation. (B) Patient facial phenotype with a long face, high forehead, horizontal eyebrows, full cheeks, long philtrum, slightly downturned mouth with an everted lower lip. Parents signed written consent for the publication of this image.

At the age of 6 months, a transfontanelar ultrasound was reported as normal. At the age of 2 years, a normal MRI was reported. At this age, basic blood chemistry and hepatic profile were within normal range. Ammonia levels measured by independent labs ranged from 150 to 172 $\mu \mathrm{mol} / \mathrm{l}$ (normal values 31-123 $\mu \mathrm{mol} / \mathrm{l}$ ) which were interpreted as a marker of a neurometabolic genetic disorder.

The patient was referred to the Genetics clinic by a neurologist after a poor response to anti-epileptic drugs and worsening of neurological symptoms, including dystonia, dysarthria, ataxia, and choreoathetosis with general rigidity.

Upon examination, the patient exhibited subtle dysmorphic facial features, namely, a long face with a high forehead, horizontal eyebrows, full cheeks a long philtrum and a slightly downturned mouth with an everted lower lip (Fig. 1B). After the initial clinical evaluation, plasma amino acids, acylcarnitines, and organic acids in urine were analyzed by mass spectrometry. Results were $\mathrm{CH} 05$ : $0.05 \mathrm{nmol} / \mathrm{ml}$ (normal value for age $<0.12$ $\mathrm{nmol} / \mathrm{ml}$ ), plasma amino acids, acylcarnitine, and organic acids in urine under normal limits. After ruling out the diagnosis of a metabolic disorder based on this biochemical test results, we decided to perform a next-generation sequencing panel with targeted DNA sequencing approach for Mendelian disorders, which captures exons of 4,813 genes previously associated to genetic disease.
Sequencing was performed with a Miseq sequencer (Illumina) using Trusight One Panel (FC-141-1006, Illumina) panel under manufacturer protocols. Sequence alignment was performed using BWA (version 0.7.9a-isis-1.0.0), and variants were called with GATK 1.6 (v1.6-23-gf0210b3) using Miseq Reporter v.2.6 and downstream variant analysis with ANNOVAR $^{7}$ using web version (http://wannovar.wglab.org/).

No variants were found in GCDH, ETFDH, ETFA, ETFB or SUGCT genes, which, when mutated, produce glutaric aciduria. A heterozygous missense variant $c$. 2839G $>$ A (p.Gly947Arg) located at exon 21 of ATP1A3 gene (NM_152296.4) was identified (Fig. 2A). This variant, rs398122887, has been independently reported as pathogenic by clinical laboratories in Clinvar database $^{6}$ and literature ${ }^{8}$. The variant was confirmed by bi-directionally Sanger sequencing using BigDye ${ }^{\circledR}$ Terminator Cycle chemistry in an Applied Biosystems 3130 Genetic Analyzer (Fig. 2). The p.G947R was not present in parental DNAs (Figs. 2B and $2 \mathrm{C}$ ) supporting a de novo origin.

After the confirmation of $\mathrm{AHC}$, the patient started treatment with flunarizine $2.5 \mathrm{mg}$ daily and control of triggering agents of hemiplegia. The patient improved from a frequency of events from 4-5 weekly (16-20 per month) to 1-2 monthly and experienced a better quality of life. 


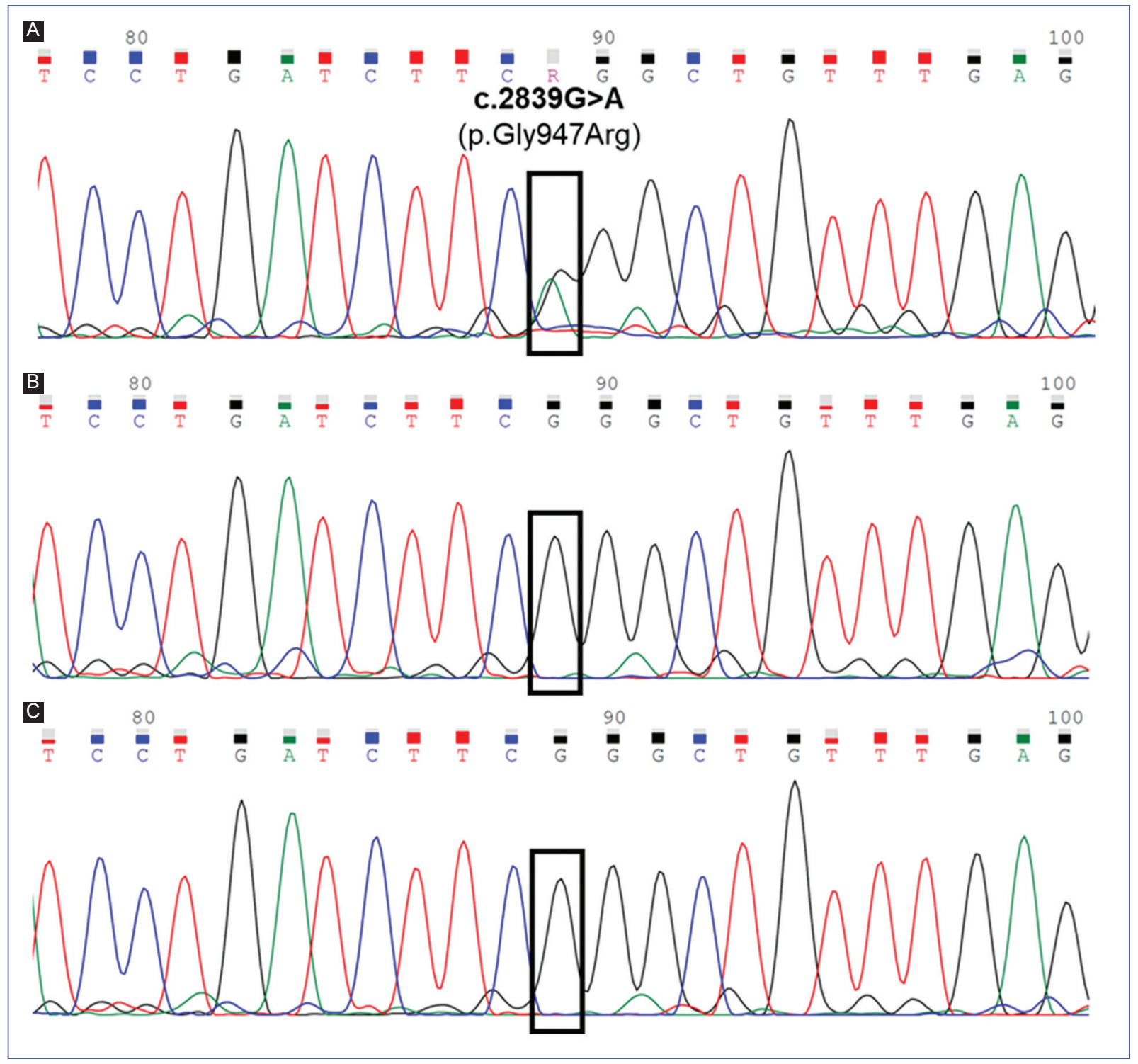

Figure 2. Partial electropherograms show the sequence of exon 21 of the ATP1A3 gene obtained by Sanger sequencing. A. Proband, the black square indicates the localization of the heterozygous pathogenic missense variant NM_152296.4:c.2839G>A (p.Gly947Arg) (rs398122887). Mother (B) and father (C) were homozygous for reference allele $\mathrm{G}$ at the $\mathrm{c} .2839$ position, supporting a de novo origin of the missense variant.

\section{Discussion}

In this patient, slightly increased levels of ammonia were misinterpreted for years by pediatricians and neurologists as an inborn error of metabolism. However, after a careful clinical exam, it was clear that the patient had no metabolic crisis and that the hemiplegia episodes were not related with protein consumption, as it is expected for inborn error of metabolism of lipids or amino acids. Using a massively parallel sequencing approach, we were able to diagnose the patient with $\mathrm{AHC}$. This is likely the first patient diagnosed with $\mathrm{AHC}$ in Latin
America. The variant p.Gly947Arg has been reported in patients of different ethnicities and their clinical presentation matches with that our patient ${ }^{4}$. Interestingly, the finding of recurrent de novo variants at position 947 of ATP1A3 suggests a mutational hotspot in this gene. The p.Gly947Arg pathogenic variant is associated with a better prognosis of AHC type 2 according to other reports in the medical literature ${ }^{4}$. This variant produces impaired $\mathrm{Na} / \mathrm{K}-\mathrm{ATP}$ ase transport activity, which results in abnormal ion gradients and depolarization membrane potential. It is considered as evidence that the partial loss of function of $\mathrm{Na} / \mathrm{K}-\mathrm{ATP}$ ase is responsible for $\mathrm{AHC}^{9}$. 
From a clinical perspective, it is important for case reports of patients of different ethnicities with ultra-rare syndromes, such as AHC to elaborate a detailed genotype-phenotype correlation, because of the highly variable clinical expressivity of ion channel diseases. Additionally, an identical ATP1A3 mutation may result in distinct phenotypes. Indeed, the ATP1A3 variant, $c$. $2767 G>A$ ( $p . A s p 923 A s n$ ), has been observed to cause both RDP and $\mathrm{AHC}^{1,10}$.

$\mathrm{AHC}$ is a poorly recognized disorder, and thus it is important for pediatricians and neurologists to be aware of this condition when performing clinical evaluations of children with seizure-like episodes or movement disorders. Diagnosis is challenging because hemiplegia episodes, which may occur only at home, may be misinterpreted by parents as an epileptic crisis. Clinicians should be aware of the combination of hemiplagia/hemiparesis without epilepsy. Some subtle dysmorphic facial features are emerging as a recognizable phenotype in $\mathrm{AHC}^{11}$; however, we acknowledge that expertise in dysmorphology is required tor recognize the AHC facial phenotype. This patient has the facial features (Fig. 1B) reported in other AHC patients ${ }^{11}$.

The patient has improved with flunarizine treatment, which illustrates the importance of an accurate and timely diagnosis in patients with rare disorders. The diagnosis of $\mathrm{AHC}$ also helped the family to receive an accurate risk of recurrence for future pregnancies.

In conclusion, massively parallel sequencing can modify our approach to diagnose ultra-rare disorders in neurology and metabolic medicine. In this patient, usage of a next generation sequencing (NGS) panel enabled a shorter and cost-effective pathway to the diagnosis, compared with the traditional method of gene-by-gene testing. This has led to a significant improvement in the quality of life of the child and the family. We hope that NGS testing will be more accessible for Latin-American public health systems in the near future.

\section{Ethical disclosures}

Protection of human and animal subjects. The authors declare that no experiments were performed on humans or animals for this study.
Confidentiality of data. The authors declare that they have followed the protocols of their work center on the publication of patient data.

Right to privacy and informed consent. The authors have obtained the written informed consent of the patients or subjects mentioned in the article. The corresponding author is in possession of this document.

\section{Acknowledgments}

To the family of the patient, for accepting to report this case and the difficult diagnostic journey.

\section{Conflicts of interest}

The authors declare no conflict of interests.

\section{Funding}

None.

\section{References}

1. Sweney MT, Newcomb TM, Swoboda KJ. The expanding spectrum of neurological phenotypes in children with ATP1A3 mutations, alternating hemiplegia of childhood, rapid-onset dystonia-parkinsonism, CAPOS and beyond. Pediatr Neurol. 2015;52:56-64. doi: 10.1016/j.pediatrneurol.2014.09.015.

2. Heinzen EL, Arzimanoglou A, Brashear A, Clapcote SJ, Gurrieri F, Goldstein DB, et al. Distinct neurological disorders with ATP1A3 mutations. Lancet Neurol. 2014;13:503-14. doi: 10.1016/S1474-4422(14)70011-0.

3. Masoud M, Prange L, Wuchich J, Hunanyan A, Mikati MA. Diagnosis and treatment of alternating hemiplegia of childhood. Curr Treat Options Neurol. 2017;19:8. doi: 10.1007/s11940-017-0444-7.

4. Panagiotakaki E, De Grandis E, Stagnaro M, Heinzen EL, Fons C, Sisodiya S, et al. Clinical profile of patients with ATP1A3 mutations in alternating hemiplegia of childhood-a study of 155 patients. Orphanet J Rare Dis. 2015;10:123. doi: 10.1186/s13023-015-0335-5.

5. Boelman C, Lagman-Bartolome AM, MacGregor DL, McCabe J, Logan WJ Minassian BA. Identical ATP1A3 mutation causes alternating hemiplegia of childhood and rapid-onset dystonia parkinsonism phenotypes. Pediatr Neurol. 2014:51:850-3. doi: 10.1016/j.pediatrneurol.2014.08.015.

6. Landrum MJ, Lee JM, Benson M, Brown GR, Chao C, Chitipiralla S, et al. ClinVar: improving access to variant interpretations and supporting evidence. Nucleic Acids Res. 2018;46:D1062-7. doi: 10.1093/nar/gkx1153.

7. Wang K, Li M, Hakonarson H. ANNOVAR: functional annotation of genetic variants from high-throughput sequencing data. Nucleic Acids Res. 2010;38:e164. doi: 10.1093/nar/gkq603.

8. Heinzen EL, Swoboda KJ, Hitomi Y, Gurrieri F Nicole S, de Vries B, et al. De novo mutations in ATP1A3 cause alternating hemiplegia of childhood. Nat Genet. 2012;44:1030-4. doi: 10.1038/ng.2358.

9. Simmons CQ, Thompson CH, Cawthon BE, Westlake G, Swoboda KJ Kiskinis $E$, et al. Direct evidence of impaired neuronal Na/K-ATPase pump function in alternating hemiplegia of childhood. Neurobiol Dis. 2018;115:29-38. doi: 10.1016/j.nbd.2018.03.009.

10. Roubergue A, Roze E, Vuillaumier-Barrot S, Fontenille MJ, Méneret A, Vidailhet $M$, et al. The multiple faces of the ATP1A3-related dystonic movement disorder. Mov Disord. 2013;28:1457-9. doi: 10.1002/mds.25396.

11. Gurrieri F, Tiziano FD, Zampino G, Neri G. Recognizable facial features in patients with alternating hemiplegia of childhood. Am J Med Genet A 2016;170:2698-705. doi: 10.1002/ajmg.a.37808. 